\title{
Retrograde Regulation of GABA Transmission by the Tonic Release of Oxytocin and Endocannabinoids Governs Postsynaptic Firing
}

\author{
Stéphane H. R. Oliet, ${ }^{1 \star}$ Dinara V. Baimoukhametova, ${ }^{2 \star}$ Richard Piet, ${ }^{1}$ and Jaideep S. Bains ${ }^{2}$ \\ ${ }^{1}$ Institut National de la Santé et de la Recherche Médicale, Unité 862, Université Victor Segalen Bordeaux 2, Bordeaux 33077, France, and ${ }^{2}$ Department of \\ Biophysics and Physiology, The Hotchkiss Brain Institute, University of Calgary, Calgary, Alberta, Canada T2N 4N1
}

\begin{abstract}
The probability of neurotransmitter release at the nerve terminal is an important determinant of synaptic efficacy. At some central synapses, the postsynaptic, or target, neuron determines neurotransmitter release probability $\left(P_{\mathrm{r}}\right)$ at the presynaptic terminal. The mechanisms responsible for this target-cell dependent control of $P_{\mathrm{r}}$ have not been elucidated. Using whole-cell patch-clamp recordings from magnocellular neurosecretory cells in the paraventricular and supraoptic nuclei of the hypothalamus, we demonstrate that inhibitory, GABA synapses specifically onto oxytocin (OT)-producing neurosecretory cells exhibit a low $P_{\mathrm{r}}$ that is relatively uniform at multiple synapses onto the same cell. This low $P_{\mathrm{r}}$ results from a two-step process that requires the tonic release of OT from the postsynaptic cell. The ambient extracellular levels of neuropeptide are sufficient to activate postsynaptic OT receptors and trigger the $\mathrm{Ca}^{2+}$-dependent production of endocannabinoids, which act in a retrograde manner at presynaptic cannabinoid $\mathrm{CB}_{1}$ receptors to decrease $\mathrm{GABA}_{\mathrm{B}} \mathrm{release}$. The functional consequence of this tonic inhibition of GABA release is that all inhibitory inputs facilitate uniformly when activated at high rates of activity. This causes inhibition in the postsynaptic cell that is sufficiently powerful to disrupt firing. $\mathrm{Blockade} \mathrm{C} \mathrm{CB}_{1}$ receptors increases $P_{\mathrm{r}}$ at these synapses, resulting in a rapid depression of IPSCs at high rates of activity, thereby eliminating the ability of afferent inputs to inhibit postsynaptic firing. By playing a deterministic role in GABA release at the afferent nerve terminal, the postsynaptic OT neuron effectively filters synaptic signals and thereby modulates its own activity patterns.
\end{abstract}

Key words: endocannabinoid; GABAergic modulation; neuropeptide; oxytocin; paraventricular; pituitary; presynaptic; supraoptic; synaptic transmission

\section{Introduction}

The effectiveness with which neurons convey information is determined primarily by the strength of their synapses. These diverse structures exhibit many forms of plasticity, including transient, activity-dependent strengthening or weakening (for review, see Zucker and Regehr, 2002; Abbott and Regehr, 2004), which is determined, primarily, by the probability of neurotransmitter release $\left(P_{\mathrm{r}}\right)$ (Zucker and Regehr, 2002). Recent observations support the idea that the target (postsynaptic) neuron may be an important determinant of $P_{\mathrm{r}}$ (Reyes et al., 1998; Gupta et al., 2000; Craig and Boudin, 2001; Baimoukhametova et al., 2004; Koester and Johnston, 2005; Watanabe et al., 2005). Although the constitutive release of endocannabinoids has been implicated in

\footnotetext{
Received June 23, 2006; revised Oct. 6, 2006; accepted 0ct. 19, 2006.

This work was supported by grants from the Canadian Institutes for Health Research (J.S.B.), the Institut National de la Santé et de la Recherche Médicale, and the Conseil Régional d'Aquitaine (S.H.R.O.). R.P. was supported by a studentship from the Ministère de l'Education Nationale, de la Recherche, et de la Technologie. J.S.B. is the recipient of an Alberta Heritage Foundation for Medical Research Senior Scholar Award. We thank Dionysia Theodosis for invaluable assistance with immunohistochemistry, Cheryl Sank for technical assistance, and the members of the Bains and Oliet laboratories for comments on previous drafts of this manuscript.

*S.H.R.O. and D.V.B. contributed equally to this work.

Correspondence should be addressed to Jaideep S. Bains, Department of Biophysics and Physiology, The Hotchkiss Brain Institute, University of Calgary, Calgary, Alberta, Canada T2N 1N4. E-mail: jsbains@ucalgary.ca. DOI:10.1523/JNEUROSCI.2676-06.2007

Copyright $\odot 2007$ Society for Neuroscience $\quad$ 0270-6474/07/271325-09\$15.00/0
}

some forms of tonic inhibition at GABA synapses (Hentges et al., 2005), neither the mechanisms through which this labile molecule can generate a long-lasting retrograde signal nor the physiological impact of such an arrangement are known.

Here we examined inhibitory GABAergic synapses onto magnocellular neurosecretory cells (MNCs) in the supraoptic (SON) and paraventricular (PVN) nuclei of the hypothalamus. GABA synapses that originate within the hypothalamus (Theodosis et al., 1986; Roland and Sawchenko, 1993) represent $\sim 40 \%$ of the total number of synapses impinging on MNCs (Gies and Theodosis, 1994), and GABA transmission critically regulates firing in MNCs (Randle and Renaud, 1987; Renaud and Bourque, 1991). Although the oxytocin (OT) and vasopressin (VP) cells that comprise the MNC population are morphologically similar and show indistinguishable levels of GABA innervation at the anatomical level (Decavel and van den Pol, 1990), there are functional differences in the nature of this inhibition: synapses terminating on VP cells depress rapidly during repetitive activation, whereas those impinging on OT neurons facilitate under the same stimulation conditions (Baimoukhametova et al., 2004). One possible reason for this discrepancy is that OT released from the postsynaptic cell (Pow and Morris, 1989; Neumann et al., 1993; Kombian et al., 1997; Ludwig et al., 2002; de Kock et al., 2003) acts in a retrograde manner to decrease GABA $P_{\mathrm{r}}$ (Kombian et al., 2000b; de Kock et 
al., 2003; Ludwig and Pittman, 2003). The localization of OT receptors (OTRs) to the postsynaptic OT cell (Ludwig and Pittman, 2003), however, argues against a direct effect on the presynaptic terminal. Instead, tonically released OT from these cells may activate local $\mathrm{Ca}^{2+}$ stores (Lambert et al., 1994; Ludwig et al., 2002) and produce a second molecule such as an endocannabinoid (eCB) (Brenowitz and Regehr, 2003; Hirasawa et al., 2004; Ohno-Shosaku et al., 2005), which would then function as the retrograde transmitter. These effects on GABA release (Kombian et al., 2002; de Kock et al., 2004) may also be an important determinant of firing patterns in these cells (Moos, 1995). For example, in response to appropriate physiological stimulation, OT neurons fire in brief high-frequency discharges that terminate quickly, whereas VP neurons exhibit longer-lasting bursts of lower frequency (Poulain et al., 1977; Belin and Moos, 1986). The ability of OT cells to generate these bursts requires the actions of OT (Freund-Mercier et al., 1983; Moos and Richard, 1989; Lambert et al., 1993; Jourdain et al., 1998).

To address this issue, we obtained whole-cell patch-clamp recordings from MNCs in the SON and PVN of rat brain slices in which we evoked GABA synaptic currents. Paired-pulse stimulation was used to estimate the relative strength of the synapse. Our data show that the relative strength of a synapse is set by eCBs released from the target cell in response to the activation of postsynaptic OTRs. By maintaining synapses in an initial "weak" or unreliable state, OT neurons paradoxically increase the impact of synaptic inhibition during high-frequency afferent discharges and consequently control their own firing behavior.

\section{Materials and Methods}

All experiments were conducted following animal care and use procedures outlined by the University of Calgary and the Universite de Bordeaux 2 in keeping with the guidelines of the Canadian and French Councils for animal care.

Slice preparation. Both male Sprague Dawley and female Wistar rats (3-8 weeks old) were used for this study. Animals were anesthetized with either isoflurane or sodium pentobarbital $(30-50 \mathrm{mg} / \mathrm{kg})$ and decapitated. The brain was quickly removed and placed in ice-cold artificial CSF (ACSF) saturated with $95 \% \mathrm{O}_{2}$ and $5 \% \mathrm{CO}_{2}$. Coronal slices $(300 \mu \mathrm{m})$ were cut with a vibratome from a block of tissue containing the hypothalamus. Slices including either the SON or PVN were hemisected along the midline and allowed to recover for at least $1 \mathrm{~h}$ before recording. A slice was then transferred into a recording chamber in which it was submerged and continuously perfused $(1-2 \mathrm{ml} / \mathrm{min})$ with ACSF at $32.5^{\circ} \mathrm{C}$. The composition of the ACSF was as follows (in $\mathrm{mM}$ ): $123 \mathrm{NaCl}, 2.5 \mathrm{KCl}, 1$ $\mathrm{Na}_{2} \mathrm{HPO}_{4}, 26.2 \mathrm{NaHCO}_{3}, 1.3 \mathrm{MgSO}_{4}, 2.5 \mathrm{CaCl}_{2}$, and 10 glucose, pH 7.4 (295 mOsm $/ \mathrm{kg})$.

Patch-clamp recording. MNCs were visually identified using infrared differential interference contrast (IR-DIC) microscopy [BX50 (Olympus Optical, Tokyo, Japan) or Axioskop FSII (Zeiss, Oberkochen, Germany)]. Patch-clamp recording pipettes $(4-7 \mathrm{M} \Omega$ ) were filled with a solution containing the following (in mM): $141 \mathrm{CsCl}, 10 \mathrm{HEPES}$, and 2 $\mathrm{Mg}$-ATP, adjusted to $\mathrm{pH} 7.1$ with $\mathrm{CsOH}$. In some experiments, $\mathrm{CsCl}$ was replaced with K-gluconate. Biocytin $(0.2 \%)$ was added to the pipette solution for identification purpose. Membrane currents were recorded using an Axopatch-1D or the Multiclamp 700A amplifier (Molecular Devices, Palo Alto, CA), low-pass filtered at 1 or $2 \mathrm{kHz}$, and digitized at 5-10 kHz using the Digidata 1322 (Molecular Devices). Series resistance $(16-20 \mathrm{M} \Omega$ ) was monitored on-line, and cells were excluded from data analysis if more than a $15 \%$ change occurred during the course of the experiment. To evoke IPSCs, either a bipolar stainless steel or a glass stimulating electrode connected to an isolated stimulator (Digitimer, Hertfordshire, UK) was placed in the hypothalamic region dorsomedial to the SON (Kombian et al., 1997) or ventrolateral to PVN. Synaptic responses were evoked at $0.05 \mathrm{~Hz}$, using square pulses of $0.1 \mathrm{~ms}$ duration, and analyzed on-line using a data acquisition and analysis software (Mo- lecular Devices; Bio-Logic, Claix, France). To study the paired-pulse facilitation ratio (PPR), two synaptic responses (P1 and P2) were evoked by two stimuli given at 50-60 ms intervals. PPR was expressed as the ratio of the amplitude of the second synaptic response over the first synaptic response (P2/P1). Stimulus trains consisting of individual $50 \mu$ s pulses delivered at one of the following frequencies, 10, 20 and $50 \mathrm{~Hz}$, were generated using a Grass Instruments (Quincy, MA) P88 stimulator. A minimum of 20 sweeps at each test frequency were collected and averaged. Each $1 \mathrm{~s}$ sweep was separated by a $10 \mathrm{~s}$ interval. In $\sim 30 \%$ of the trials, this stimulation protocol resulted in robust increase in the frequency of quantal IPSCs. This effect has been reported previously in the hypothalamus for excitatory synapses (Kombian et al., 2000a). This increase in GABA IPSC frequency can outlast the stimulus train and can lead to a substantial membrane hyperpolarization. Because we were interested in limiting our examination exclusively to the impact of evoked inhibition on postsynaptic spiking, these cells were not used for analysis in the present study.

Immunohistochemistry. In some experiments, recorded magnocellular neurons filled with biocytin $(1 \mathrm{mg} / \mathrm{ml})$ were identified by immunocytochemistry. To this end, slices were fixed by immersion in $4 \%$ paraformaldehyde and $0.15 \%$ picric acid ( $2 \mathrm{~h}$, room temperature) and then stored in $4 \%$ paraformaldehyde for several days at $4^{\circ} \mathrm{C}$. Biocytin was revealed with streptavidin-conjugated 7-amino-4-methyl-coumarin-3-acetic acid (Bio-Sys, Karben, Germany) diluted 1:200. Sections $(50 \mu \mathrm{m})$ were then obtained with a vibratome after embedding of the slices in $4 \%$ agar. Sections containing biocytin-positive neurons were then incubated for $4 \mathrm{~d}$ at $4^{\circ} \mathrm{C}$ in a mixture of monoclonal mouse antibodies raised against OT-related neurophysin (diluted 1:1000; gift from H. Gainer, National Institutes of Health, Bethesda, MD) and of polyclonal rabbit antibodies raised against VP-related neurophysin (diluted 1:4000; gift from A. Robinson, University of California, Los Angeles, Los Angeles, CA). Immunoreactivity for OT-related neurophysin was visualized with goat antimouse Ig conjugated to fluorescein isothiocyanate (Bio-Sys) diluted 1:400 and that of VP-related neurophysin with goat anti-rabbit Ig conjugated to Texas Red (Bio-Sys) diluted 1:800 (2 h, room temperature). All antibodies were diluted in $0.25 \%$ TBS-BSA containing $0.5 \%$ Triton $\mathrm{X}-100$. Slices were mounted in Vectashield and examined under epifluorescence with appropriate filters (DMR; Leica, Nussloch, Germany) microscope.

Data analysis. Data were digitized (pClamp 9; Molecular Devices) and stored on computer for off-line analysis. Evoked currents were analyzed using Clampex 9 (Molecular Devices). Before calculating the amplitude of individual IPSCs in the train, traces were examined by eye, and those in which spontaneous IPSCs obscured the peak of the evoked response were discarded. The amplitude of the synaptic current was calculated from the baseline (current before the first evoked response) to the peak of each evoked response. For clarity, the stimulus artifacts have been removed digitally from the traces depicted. All values shown are mean \pm SEM. Data points were compared using ANOVA with a post hoc NewmanKeuls test (multiple groups) or Student's $t$ test (two groups).

Chemicals. All drugs were bath applied. Appropriate stock solutions were made and diluted with ACSF just before application. Drugs used were CNQX, biocytin, and WIN 55,212-2 [R-(+)-(2,3-dihydro-5-methyl-3-[(4morpholinyl)methyl]pyrol[1,2,3-de]-1,4-benzoxazin-6-yl)(1-naphthalenyl) methanone monomethanesulfonate] (WIN) (Sigma, St. Louis, MO), AM-251 [N-1-(2,4-dichlorophenyl)-5-(4-iodophenyl)-4-methyl- $N$-1piperidinyl- $1 \mathrm{H}$-pyrazole-3-carboxamide] (Tocris Cookson, Ballwin, $\mathrm{MO}$ ), and oxytocin (Bachem, Bubendorf, Switzerland). The Manning compound was either purchased from Bachem or kindly provided by Dr. Maurice Manning (Medical College of Ohio, Toledo, OH).

\section{Results}

Recordings were obtained from MNCs in either the SON or the PVN. Using IR-DIC optics, neurons were identified morphologically before obtaining recordings. At the start of the recording, neurons were tentatively classified as MNCs based on previously described electrical properties (Stern and Armstrong, 1997): VP neurons generally exhibit linear $I-V$ relationships, whereas OT 
A

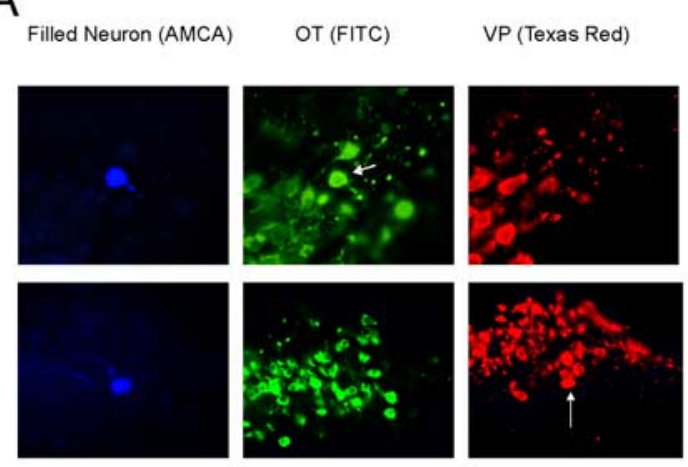

B
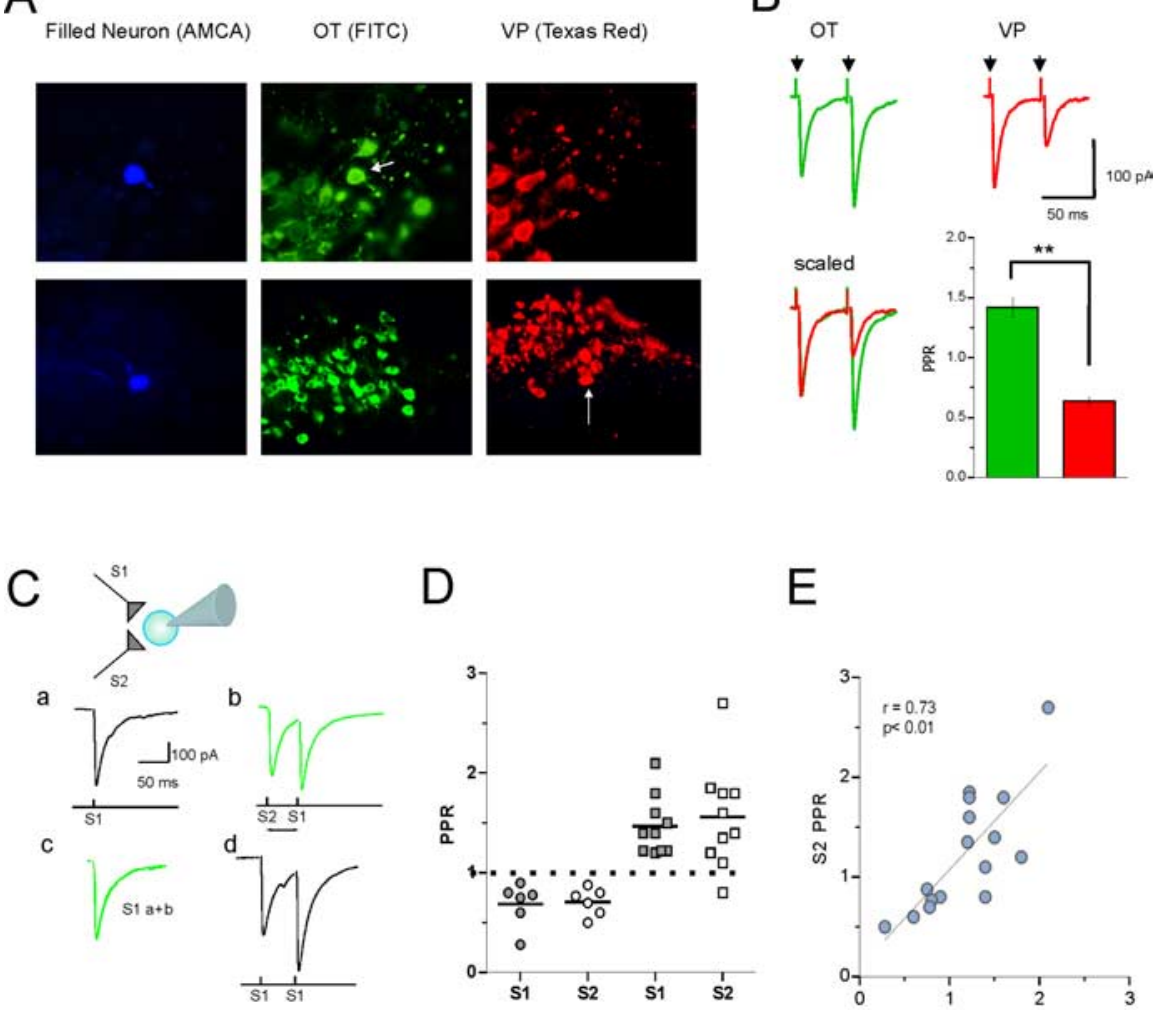

$E$

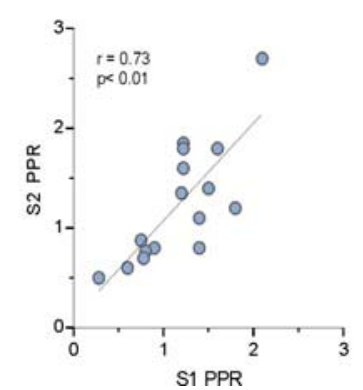

Figure 1. $\quad P_{\mathrm{r}}$ at GABA synapses is target-cell dependent. $\boldsymbol{A}$, MNCs were filled with biocytin and identified with post hoc immunocytochemical processing. Top depicts a biocytin-filled cell that was positive for OT neurophysin (arrow) but negative for VP. Bottom depicts a biocytin-filled cell that was negative for OT but positive for VP (arrow). B, Examples of synaptic currents obtained from immuno-identified OT and VP cells in both SON and PVN in response to paired stimulation. OT cells in both nuclei exhibited PPF (PPR, $1.42 \pm 0.09 ; n=22)$, whereas VP cells exhibited PPD (PPR, $0.64 \pm 0.04 ; n=16)$. Data are summarized in bar graph. $\boldsymbol{C}$, Two independent afferent pathways were stimulated while a recording was obtained from a single MNC. Independence was tested by first stimulating one pathway $(\mathrm{S} 1 ; \boldsymbol{a})$ and then confirming that previous stimulation of the second pathway (S2) had no effect on the amplitude of the evoked response from $S 1(\boldsymbol{b}, \boldsymbol{c})$. The $S 1$ pathway exhibited PPF $(\boldsymbol{d})$. D, Stimulation of $S 2$ resulted in a PPR that was not different from the PPR obtained from S1 ( $p>0.05 ; n=16$ cells), as expected if $P_{r}$ is governed by the postsynaptic cell. $\boldsymbol{E}$, There was a strong correlation between PPR in S1 and PPR in S2.

neurons exhibit a mild rectification at negative potentials. During the course of the experiment, cells were filled with biocytin and processed post hoc to definitively determine cell phenotype.

Target cell dictates release probability at inhibitory synapses We have shown previously that, in MNCs of the PVN, $P_{\mathrm{r}}$ of GABA is correlated with the phenotype of the postsynaptic cell (Baimoukhametova et al., 2004). In general, GABA transmission onto VP-immunopositive cells display paired-pulse depression (PPD), and GABA synapses onto OT cells display paired-pulse facilitation (PPF). This measure of short-term plasticity is indicative of $P_{\mathrm{r}}$ at the activated synapse (Zucker and Regehr, 2002). In general, PPF is consistent with low $P_{\mathrm{r}}$, whereas PPD is indicative of high $P_{\mathrm{r}}$. To test whether this observation of differential $P_{\mathrm{r}}$ was a general feature of OT and VP neurons, we examined PPR in MNCs of the SON. To test this hypothesis, we obtained recordings from SON neurons and examined evoked inhibitory transmission to these cells. The phenotype of these cells was positively identified by filling the cells with biocytin and performing a post hoc immunohistochemical analysis with antibodies targeted to either OT or VP (Fig. 1 A). In immuno-identified OT cells, GABA synapses had a low initial release probability $\left(\right.$ low $P_{\mathrm{r}}$ ), with a PPR of $1.42 \pm 0.09(n=22)$ (Fig. $1 B)$. In contrast, GABA synapses onto VP cells exhibited a high initial release probability (high $\left.P_{\mathrm{r}}\right)$, with a PPR of $0.64 \pm 0.04(n=$ $16 ; p<0.01$ compared with OT cells) (Fig. $1 B)$. These data are similar to those obtained in the PVN (Baimoukhametova et al., 2004). To directly test whether synapse reliability was indeed determined by the postsynaptic cell, we recorded from a single neuron while stimulating from two different pathways. We first established that stimulation of each pathway elicited an IPSC. Then selective stimulation of one pathway was immediately followed (within $20 \mathrm{~ms}$ ) by stimulation of the second pathway. We noted that stimulating one pathway had no effect on the synaptic current generated by stimulation of the second pathway $(n=16)$ (Fig. $1 C)$. This lack of interaction between the two subsets of synapses is consistent with the activation of two separate and independent pathways. PPR in one pathway onto a cell was a strong predictor of PPR in the other pathway onto that same cell $(p>0.05$; $n=16$ cells) (Fig. $1 D, E$ ). These findings are consistent with the hypothesis that $P_{\mathrm{r}}$ of the afferent GABA synapses onto MNCs is determined by the postsynaptic cell, yet the mechanisms through which the postsynaptic cell can control $P_{\mathrm{r}}$ are not known.

\section{Constitutive activation of OT receptors is responsible for low $P_{r}$}

In addition to releasing their peptide contents from nerve terminals in the posterior pituitary, both OT and VP neurons release peptides from their dendrites (Pow and Morris, 1989). Whereas VP depresses only excitatory glutamatergic transmission (Kombian et al., 2000b), OT depresses both excitatory and inhibitory transmission (Kombian et al., 1997, 2002; de Kock et al., 2003, 2004). We hypothesized that synaptic unreliability at GABA synapses impinging onto OT cells may result from local constitutive release of OT (Pow and Morris, 1989; Neumann et al., 1993). To investigate this possibility, we examined the impact of the OTR antagonist Manning Compound (MC) $(10 \mu \mathrm{M})$ on evoked IPSCs. In OT cells, the amplitude of the evoked IPSCs increased significantly in the presence of OTR antagonist (1.33 \pm 0.17 as a fraction of control; $n=12 ; p<0.01$ ) (Fig. $2 A$ ). Hence, synapses were strengthened by blocking OTRs. We also tested for the effects of MC on synaptic GABA transmission onto VP cells. Here, we observed no change in the amplitude of the synaptic response ( $1.11 \pm 0.33$ as a fraction of control; $n=7 ; p>0.05)$ (Fig. $2 A$ ). The increase in IPSC amplitude at GABA synapses onto OT cells was accompanied by a decrease in the PPR (control PPR, $1.47 \pm 0.19 ; \mathrm{MC} \mathrm{PPR}, 0.90 \pm 0.08 ; n=12 ; p<0.01$ ) (Fig. 2 B). In contrast, there was no effect on GABA $P_{\mathrm{r}}$ at synapses onto VP cells (control PPR, $0.64 \pm 0.04 ; \mathrm{MC} \mathrm{PPR}, 0.74 \pm 0.17 ; n=7 ; p>0.05$ ) (Fig. $2 B$ ).

These observations are consistent with our hypothesis that the constitutive release of OT maintains GABA synapses onto OT cells in an unreliable state. Interestingly, OTRs are $\mathrm{G}_{\mathrm{q}}$-coupled receptors that are present on the OT neurons (Ludwig and Pitt- 
man, 2003), but evidence for their existence on presynaptic nerve terminals in the hypothalamus is sparse. This raises the possibility that OTR activation may be an obligatory first step that leads to the production of a retrograde messenger.

\section{Tonic $\mathrm{CB}_{1}$ receptor activation mimics} effects of $\mathrm{OT}$ receptor activation

On glutamatergic terminals in the SON, OT acts in synergy with eCBs to decrease neurotransmitter release (Hirasawa et al., 2004). To determine whether eCBs are recruited as retrograde messengers in the regulation of $P_{\mathrm{r}}$ at inhibitory synapses, we conducted pharmacological experiments using a compound (AM-251) that specifically blocks the $\mathrm{CB}_{1}$ receptor $\left(\mathrm{CB}_{1} \mathrm{R}\right)$. Bath application of AM-251 (5 $\mu \mathrm{M})$ significantly increased the amplitude of evoked IPSCs in OT neurons $(1.30 \pm 0.13$ as a fraction of control; $n=14 ; p<0.01$ ) (Fig. $2 C)$ but had no effect on the amplitude of IPSCs in VP neurons $(0.90 \pm 0.13$ as a fraction of control; $n=7 ; p>0.05$ ) (Fig. $2 C)$. The increase in the amplitude of IPSCs onto OT neurons was accompanied by a decrease in the PPR (control PPR, $1.87 \pm$ 0.19; AM-251 PPR, $0.96 \pm 0.08 ; n=14$; $p<0.01$ ) (Fig. 2D). There was no change in presynaptic reliability at GABA synapses onto VP neurons (control PPR, $0.57 \pm 0.12$; AM-251 PPR, $0.57 \pm 0.12$; $n=7 ; p>0.05$ ) (Fig. 2D). Collectively, these observations strongly implicate tonic activation of both OTRs and $\mathrm{CB}_{1}$ Rs in maintaining low $P_{\mathrm{r}}$ at GABA synapses onto OT neurons. Previous reports, however, have demonstrated that exogenous application of OT can also depress transmission at GABA synapses (de Kock et al., 2003) onto OT MNCs, suggesting that tonic release does not completely saturate OTRs. To test whether the system under examination here was still amenable to additional manipulation, we conducted experiments in which we directly activated either the OTRs or the $\mathrm{CB}_{1} \mathrm{Rs}$.

\section{Depression of GABA release by} exogenous $\mathrm{OT}$ or $\mathrm{CB}_{1}$ receptor agonists Application of OT $(1 \mu \mathrm{M})$ decreased the amplitude of the evoked response in OT neurons $(0.68 \pm 0.14 \%$ as a fraction of control; $n=9$; $p<0.01$ ) (Fig. $2 E$ ), which is consistent with previous work (de Kock et al., 2003), but failed to decrease the evoked response in VP neurons. In fact, we observed a small increase in the amplitude of the response in these neurons after OT application $(1.12 \pm$ $0.08 ; n=7 ; p<0.05)$. The decrease in amplitude was accompanied by an increase in the PPR in OT cells (control PPR, $1.37 \pm$ 0.17; OT PPR, $2.19 \pm 0.26 ; n=9 ; p<0.01$ ) (Fig. $2 F$ ). There was

\section{C}

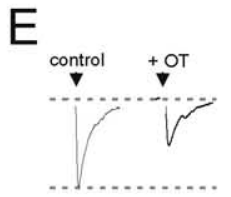

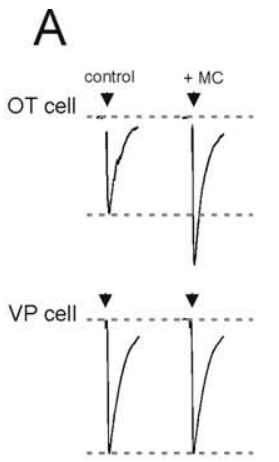

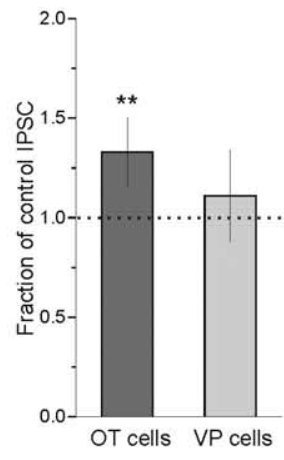

B

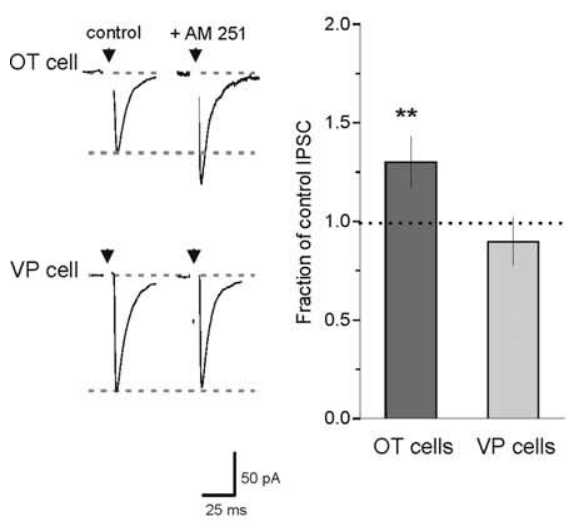

D
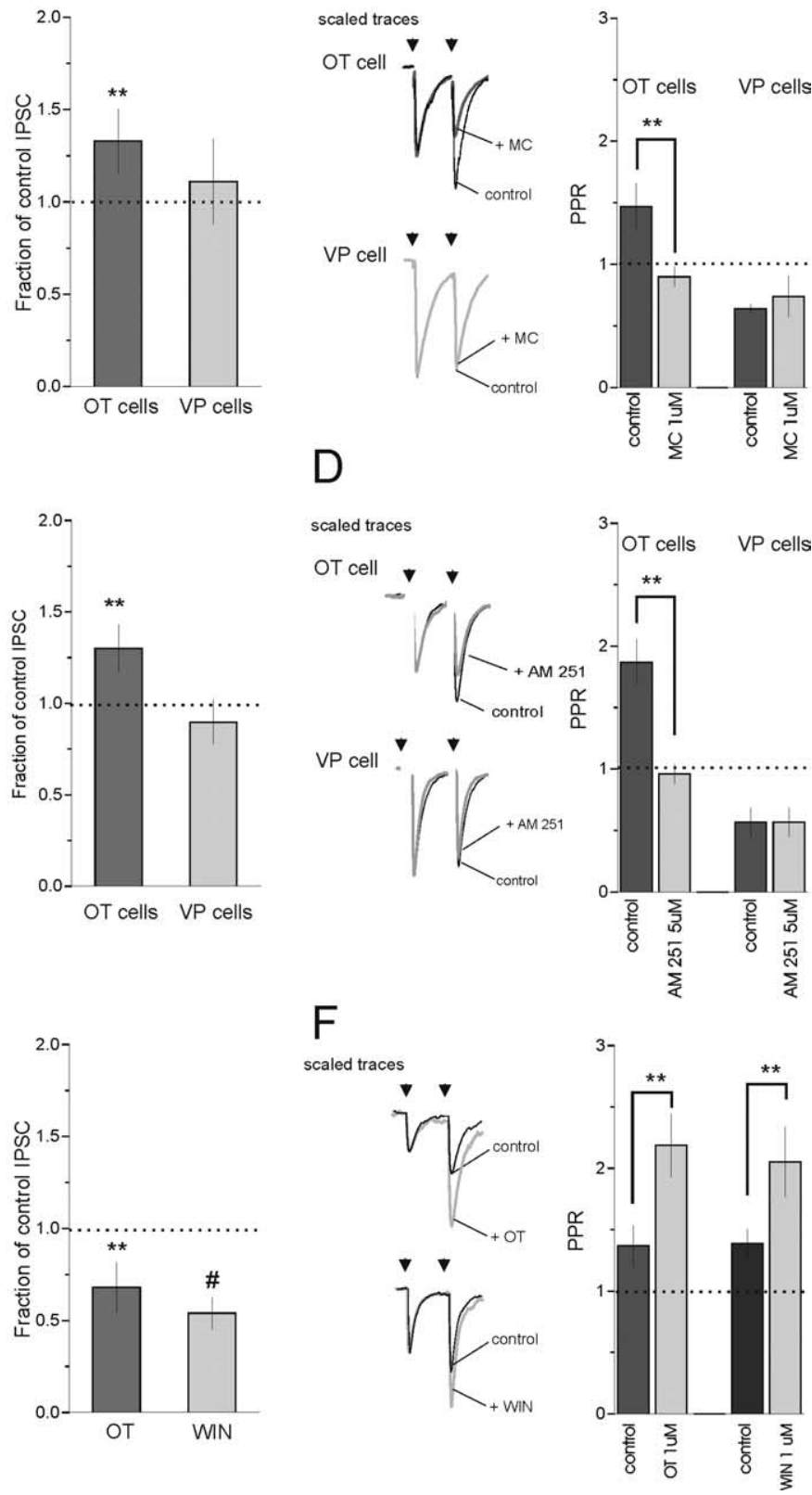

Figure 2. Control of $P_{\mathrm{r}}$ by retrograde transmitters. $A$, Exogenous application of the $0 \mathrm{~T}$ receptor antagonist $\mathrm{MC}(10 \mu \mathrm{M})$ increases amplitude of IPSC in 0 T cells $(1.33 \pm 0.17$ as a fraction of control; $n=12 ; p<0.01)$ but not VP cells $(1.11 \pm 0.33$ as a fraction of control; $n=7 ; p>0.05)$. Representative traces are left, and summary of effects of $M C$ on evoked responses are right. $\boldsymbol{B}, \mathrm{MC}$ decreases PPR in $0 \mathrm{~T}$ cells (control PPR, $1.47 \pm 0.19 ; \mathrm{MCPPR}, 0.90 \pm 0.08 ; n=12 ; p<0.01$ ) but has no effect on PPR in VP cells (control PPR, $0.64 \pm 0.04$; MCPPR, $0.74 \pm 0.17 ; n=7 ; p>0.05$ ). Representative scaled traces are left, and summary of effects of MC on PPR are right. $C$, Exogenous application of the $\mathrm{CB}_{1}$ receptor antagonist AM- $251(5 \mu \mathrm{M})$ increases the amplitude of IPSCs in 0 T cells $(1.30 \pm 0.13$ as a fraction of control; $n=14 ; p<0.01)$ but notVP cells $(0.90 \pm 0.13$ as a fraction of control; $n=7 ; p>0.05)$. Representative traces are left, and summary of effects of AM-251 on evoked responses are right. $D$, AM-251 decreases PPR in 0T cells (control PPR, $1.87 \pm 0.19 ;$ AM-251 PPR, $0.96 \pm$ $0.08 ; n=14 ; p<0.01$ ) but has no effect on VP cells (control PPR, $0.57 \pm 0.12 ; \mathrm{AM}-251$ PPR, $0.57 \pm 0.1 ; n=7 ; p>0.05$ ). Representative scaled traces are left, and summary of effects of AM-251 on PPR are right. E, IPSC amplitude was decreased by application of either OT (1 $\mu \mathrm{m} ; 0.68 \pm 0.14 \%$ as a fraction of control; $n=9 ; p<0.01)$ or the $\mathrm{CB}_{1}$ RagonistWIN $(1 \mu \mathrm{m} ; 0.54 \pm 0.09$ as a fraction of control; $n=$ $6 ; p<0.01)$. Representative traces are left, and summary of effects of $0 \mathrm{~T}$ or WIN on evoked responses are right. $\boldsymbol{F}$, PPR was also increased in the presence of either 0T (control PPR, 1.37 $\pm 0.17 ; 0 \mathrm{TPPR}, 2.19 \pm 0.26 ; n=9 ; p<0.01$ ) or WIN (control PPR, $1.39 \pm 0.12 ; \mathrm{WINPPR}$, $2.05 \pm 0.29 ; n=6 ; p<0.01) .{ }^{* *} p<0.01 ;{ }^{*} p<0.01$.

no change in PPR in VP cells (control PPR, $0.63+0.09$; OT PPR, $0.60 \pm 0.05 ; n=7 ; p>0.05)$. We next tested whether direct activation of the $\mathrm{CB}_{1} \mathrm{R}$ would mimic the effects of exogenous OT on GABA transmission. Bath application of the $\mathrm{CB}_{1}$ receptor 
agonist WIN $(1 \mu \mathrm{M})$ decreased the amplitude of the evoked IPSC onto OT neurons ( $0.54 \pm 0.09$ as a fraction of control; $n=6 ; p<$ 0.01 ) (Fig. $2 E$ ). These changes were accompanied by an increase in the PPR (control PPR, $1.39 \pm 0.12$; WIN PPR, $2.05 \pm 0.29 ; n=$ $6 ; p<0.01$ ) (Fig. $2 F$ ). Interestingly, WIN also decreased the amplitude of IPSCs onto VP neurons $(0.62 \pm 0.06 ; n=5 ; p<$ 0.01 ), but this was not accompanied by a change in PPR (control PPR, $0.82 \pm 0.13$; WIN PPR, $0.84 \pm 0.13 ; n=5 ; p>0.05$ ). These findings indicate that, although both OTRs and $\mathrm{CB}_{1}$ Rs are tonically active, there is additional capacity in this system to further decrease GABA release.

\section{$\mathrm{CB}_{1}$ receptors are necessary and sufficient for maintaining synapses in an unreliable state}

To determine whether OT and eCB pathways converge or are activated in parallel to depress GABA release, we conducted an occlusion experiment in which we first blocked the $\mathrm{CB}_{1} \mathrm{R}$ and then the OTR. In this experiment, blockade of the $\mathrm{CB}_{1} \mathrm{R}$ increased the amplitude of the IPSC as above. The subsequent application of the OTR antagonist MC at a dose $(1 \mu \mathrm{M})$ that robustly increased IPSC amplitude by itself (see above) no longer affected IPSC amplitude (AM-251, $1.30 \pm 0.13$ of control vs AM-251 plus MC, $1.33 \pm 0.08$ of control; $n=4 ; p>0.05$; or PPR AM-251, 0.96 \pm 0.08 vs AM-251 plus MC, $1.05 \pm 0.13 ; n=4 ; p>0.05$ ) (Fig. $3 A$ ). Next we determined the sequence in which these receptor systems were activated. We first blocked the $\mathrm{CB}_{1} \mathrm{R}$ with $\mathrm{AM}-251$, which increased IPSC amplitude and decreased PPR (Fig. $3 A, B$ ), and then applied exogenous OT $(1 \mu \mathrm{M})$. Under these conditions, OT still decreased the amplitude of the evoked IPSC $(0.59 \pm 0.11$ as a fraction of control; $n=4 ; p<0.01$ ) (Fig. $3 A$ ), but this was not accompanied by a change in the PPR (AM-251 PPR, $0.96 \pm 0.08$; AM-251 plus OT PPR, $1.12 \pm 0.20 ; n=4 ; p>0.05$ ) (Fig. $3 B$ ). This result indicates that the presynaptic action of OT is compromised by AM-251, whereas its previously reported postsynaptic inhibitory action on $\mathrm{GABA}_{\mathrm{A}}$ receptors (Brussaard et al., 1996) is unaffected. To test whether the $\mathrm{CB}$ system can depress GABA release independent of the OT system, we blocked the OTR and then attempted to activate the $\mathrm{CB}_{1} \mathrm{R}$ with exogenous WIN. In this experiment, WIN decreased IPSC amplitude $(0.55 \pm 0.10$ of control; $n=4 ; p<0.01$ ) (Fig. $3 A$ ) and also increased the PPR (MC PPR, $0.90 \pm 0.08$; MC plus WIN PPR, $1.88 \pm 0.33 ; n=4$ ) (Fig. $3 B$ ). Together, these findings indicate that activation of the $\mathrm{CB}_{1} \mathrm{R}$ is both necessary for the effects of OT on GABA release and sufficient, when activated by itself, to decrease release. Conversely, OTR activation in the presence of $\mathrm{CB}_{1} \mathrm{R}$ blockade only depressed transmission through an exclusively postsynaptic mechanism. This provides evidence for a logical sequence of actions in which the observed "presynaptic" actions of OT on GABA transmission depend entirely on $\mathrm{CB}_{1}$ receptor activation.

\section{Increases in postsynaptic $\mathrm{Ca}^{2+}$ are necessary for tonic depression on GABA transmission}

The release of eCBs from the postsynaptic cell requires a robust increase in intracellular $\mathrm{Ca}^{2+}$ (Brenowitz and Regehr, 2003; Ohno-Shosaku et al., 2005). The postsynaptic actions of OT on $\mathrm{GABA}_{\mathrm{A}}$ receptors also require an increase in $\mathrm{Ca}^{2+}$ (Brussaard et al., 1996), consistent with the fact that activation of OTRs increases $\mathrm{Ca}^{2+}$ in the OT neuron (Lambert et al., 1994). To test whether ambient release of eCBs and the subsequent modulation of GABA release onto OT cells was driven by elevated levels of intracellular $\mathrm{Ca}^{2+}$, we conducted experiments in which we clamped postsynaptic $\mathrm{Ca}^{2+}$ by including the $\mathrm{Ca}^{2+}$ chelator EGTA $(10 \mathrm{~mm})$ in the patch pipette. In this experiment, we ob-
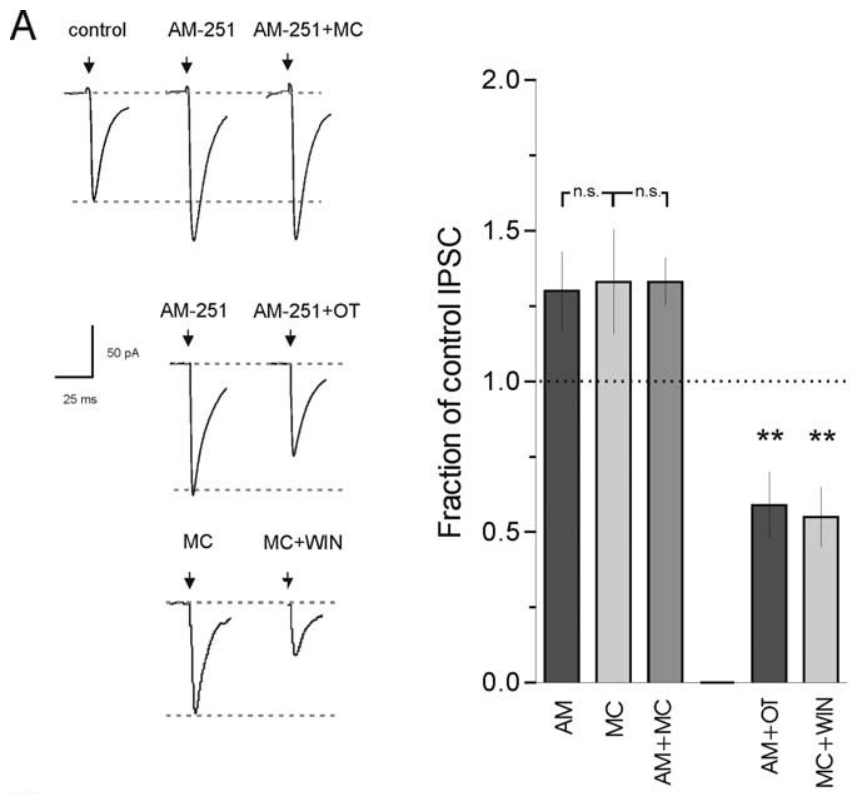

B
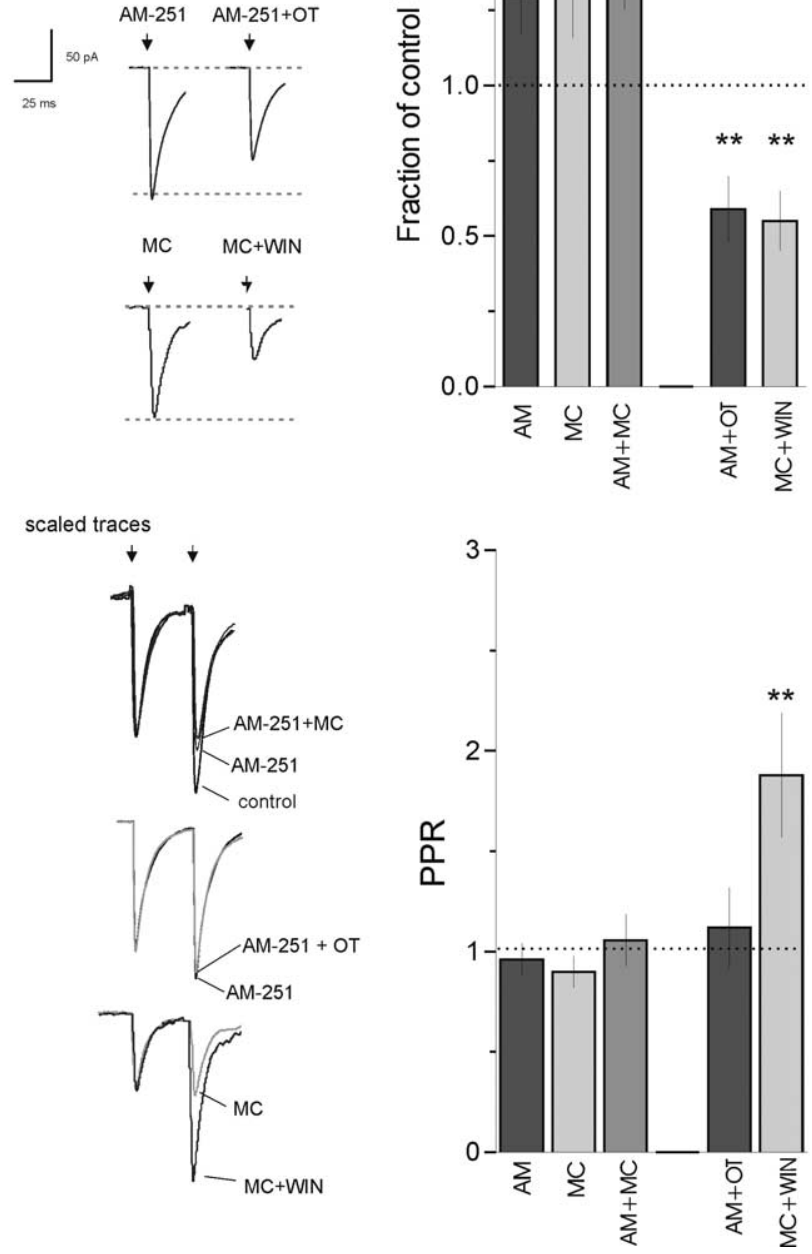

Figure 3. OT recruits the eCB system to depress GABA release. $A$, Representative traces show that blockade of $\mathrm{CB}_{1}$ receptor increases the evoked response $(1.30 \pm 0.13$ of control; $n=4)$, but there is no additional enhancement during blockade of OTRs (AM-251 plus MC, $1.33 \pm 0.08$ of control; $n=4 ; p>0.05$ ). Middle row shows decrease in IPSC amplitude when 0T is applied in the presence of AM-251 ( $0.59 \pm 0.11$ as a fraction of control; $n=4 ; p<0.01)$. Bottom row shows effect of exogenous WIN ( $1 \mu \mathrm{m})$ on IPSC in the presence of MC ( $0.55 \pm 0.10$ of control; $n=4 ; p<0.01$ ). Data are summarized at the right. $B$, Scaled traces show no effect of $M C$ on PPR when slice is pretreated with AM-251 (AM-251, $1.30 \pm 0.13$ of control vs AM-251 plus MC, $1.33 \pm 0.08$ of control; $n=4 ; p>0.05$; top traces). Similarly, exogenous 0 T has no effect on PPR in the presence of AM-251 (AM-251 PPR, $0.96 \pm 0.08$; AM-251 plus 0T PPR, $1.12 \pm 0.20$; $n=4 ; p>0.05$; middle), but WIN still effectively increased PPR in the presence of MC (MCPPR, $0.90 \pm 0.08 ;$ MC plus WIN PPR, $1.88 \pm 0.33 ; n=4$; bottom row). The PPR data are summarized at the right. ${ }^{* *} p<0.01$.

served a slow increase in the amplitude of the evoked IPSC during the first 15 min of the recording (Fig. 4A), consistent with the relief of a tonic inhibition dependent on intracellular postsynaptic $\mathrm{Ca}^{2+}$. Because $\mathrm{Ca}^{2+}$ also inhibits the GABA receptor postsynaptically, this increased IPSC amplitude could reflect the relief of either OT-mediated postsynaptic or presynaptic inhibitory tone, or both. We thus tested for changes in PPR once the recording had stabilized to discriminate between these two possibilities. In 

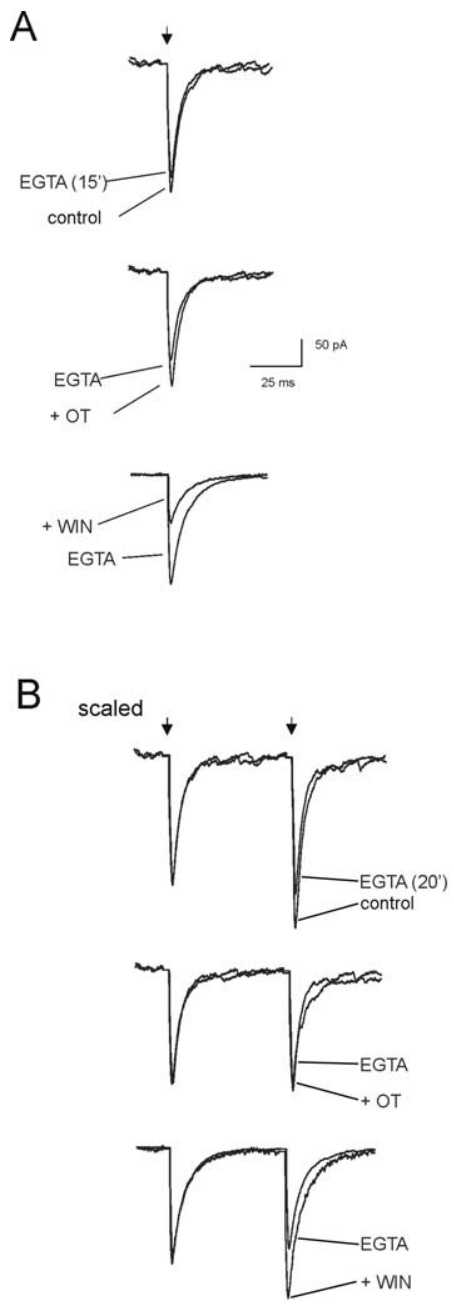

require functional $\mathrm{Ca}^{2+}$ signaling in the postsynaptic cell. In contrast, the impact of the exogenous $\mathrm{CB}_{1}$ receptor agonist WIN was not affected by increased buffering of $\mathrm{Ca}^{2+}$ in the postsynaptic cell. WIN decreased IPSC amplitude $(0.43 \pm 0.12$ as a fraction of control; $n=5$; $p<0.01$ ) (Fig. $4 A$ ) and increased PPR (WIN, $1.35 \pm 0.13 ; n=6 ; p<0.05$ compared with PPR in EGTA) (Fig. $4 B)$. These results confirm the sequence of events whereby the OTR activation precedes the production of eCBs and indicate that postsynaptic $\mathrm{Ca}^{2+}$ is necessary for the production of the retrograde messenger that tonically regulates $P_{\mathrm{r}}$ at GABA synapses onto OT cells.

\section{Blockade of $\mathrm{CB}_{1}$ receptors eliminates effects of high- frequency activation on disruption of spike activity}

To determine the physiological contribution of synaptic reliability at GABA synapses, we next determined the impact of $P_{\mathrm{r}}$ on postsynaptic currents during high-frequency afferent discharges. We delivered trains of presynaptic stimuli at three different frequencies, $-10,20$, and $50 \mathrm{~Hz}$. In synapses that exhibited a PPR $>1$ (OT neurons), robust frequency-dependent facilitation was evident (Fig. 5A, $B$ ). In contrast, initially reliable synapses (PPR $<1$ ) (VP neurons) exhibited robust depression when activated using the same stimulation parameters (data not shown) (Baimoukhametova et al., 2004). In four cells, we directly tested whether eCB inhibition would affect the steady-state inhibition [the average synaptic current for pulses 10-20 of a 20 stimulus train $\left(\right.$ IPSC $\left._{\mathrm{ss}}\right)$ ]. In control conditions, the facilitation at this synapse resulted in a robust IPSC $_{\mathrm{ss}}$ of $153.7 \pm 5.9 \mathrm{pA}$ (Fig. 5B). After inhibition of $\mathrm{CB}_{1} \mathrm{Rs}$, these synapses exhibited a depression in response to a $20 \mathrm{~Hz}$ train (Fig. $5 A, B$ ). The absolute IPSC $_{\mathrm{ss}}$ in these cells was $66.3+3.9 \mathrm{pA}$, a decrease of $\sim 60 \%$ compared with control $(p<0.0001 ; n=4)$.

In an effort to determine the physiological impact of this short-term plasticity, we activated the presynaptic pathway with a $20 \mathrm{~Hz}, 1 \mathrm{~s}$ stimulus while recording from a postsynaptic cell that was depolarized to generate a stable level of spiking. Synaptic stimulation of facilitating synapses onto OT cells resulted in an abrupt cessation of firing in the postsynaptic cell (control spike frequency, $7.64 \pm 0.11 \mathrm{~Hz}$; spike frequency during afferent stimulation, $1.33 \pm 0.11 ; p<0.01 ; n=8$ ). The firing rate recovered within $0.5 \mathrm{~s}$ of terminating the stimulation protocol (spike frequency of $5 \mathrm{~s}$ epoch after stimulation, $7.51 \pm 0.16 \mathrm{~Hz}$ ). In contrast, stimulating reliable synapses onto VP cells, at $20 \mathrm{~Hz}$, had no effect on postsynaptic firing $(n=8 ; p>0.05$; data not shown). These data indicate that synapses with a low $P_{\mathrm{r}}$ are more effective at disrupting firing when activated at high rates of activity.

Finally, to test the contribution of tonic activation of the $\mathrm{eCB}$ system and the subsequent depression of GABA release on postsynaptic activity, we repeated the current-clamp experiments in which afferents were activated at $20 \mathrm{~Hz}$ for $1 \mathrm{~s}$. In OT cells, this experimental manipulation resulted in a cessation of firing (control spike frequency, $6.34 \pm 0.36 \mathrm{~Hz}$; spike frequency during afferent stimulation, $1.47 \pm 0.67 ; p<0.01 ; n=5$ ) (Fig. $5 C$ ). The $\mathrm{CB}_{1}$ antagonist AM-251 was then applied, and this experiment was repeated in these same cells. Under these conditions, $20 \mathrm{~Hz}$, $1 \mathrm{~s}$ afferent stimulation still decreased spike activity (control spike frequency, $6.84 \pm 0.19 \mathrm{~Hz}$; spike frequency during afferent stimulation, $4.13 \pm 0.13 ; n=5$ ) (Fig. $5 D$ ), but the impact of inhibition was significantly less effective $(p<0.001)$ when compared with spike activity during an afferent train in the absence of AM-251. 
A Control

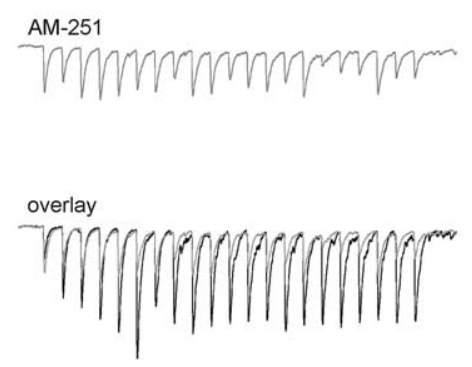

C

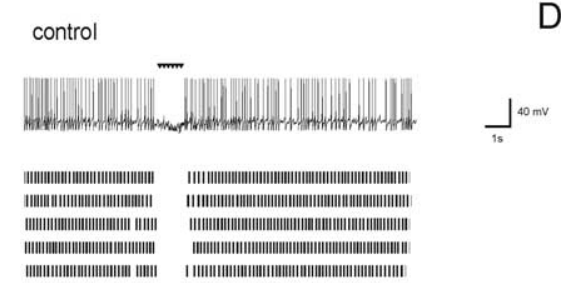

B
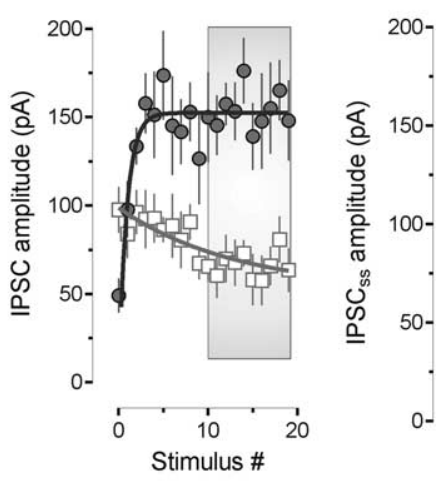

AM-251

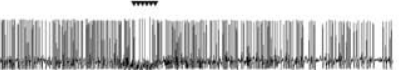

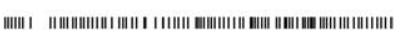

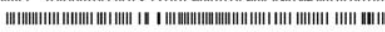

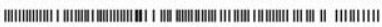

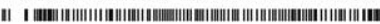

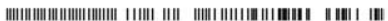

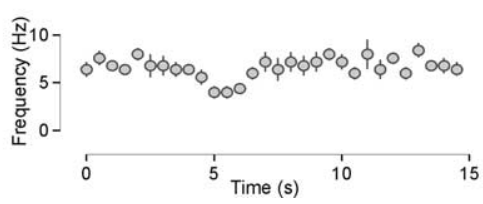

the target cell and not the afferent input that determines the probability with which GABA is released in response to a single action potential. This target-cell regulation of GABA $P_{\mathrm{r}}$ appears to be a general property of MNCs, with cells in both the PVN and SON exhibiting virtually identical response properties. By stimulating multiple pathways onto an individual cell, we demonstrated that, although the pathways activated may be independent, their behavior (facilitation or depression) for a given cell is invariant. Although targetcell-dependent modulation of GABA release probability has been reported previously (Reyes et al., 1998; Gupta et al., 2000; Rozov et al., 2001; Koester and Johnston, 2005), there have been few descriptions of the mechanisms used by individual postsynaptic neurons to regulate $P_{\mathrm{r}}$. Our results indicate that it is the constitutive release of OT from OT neurons that acts as the trigger to maintain these synapses in an unreliable state. We saw no evidence for any OT-mediated effects on GABA synapses onto VP cells, suggesting that there is little intermingling in the signaling between the two cell types. This probably reflects, to some extent, the relative anatomical segregation between OT and VP neurons in the PVN and SON (van den Pol, 1982). The actions of OT on neurotransmission in the SON have been well documented. OT release from dendrites (Pow and Morris, 1989) decreases the release of both GABA (de Kock et al., 2003) and glutamate (Kombian et al., 1997) and, additionally, through a postsynaptic, $\mathrm{Ca}^{2+}$-dependent mechanism, decreases the efficacy of $\mathrm{GABA}_{\mathrm{A}}$ receptors (Brussaard et al., 1996). OT can also have longlasting effects on dendritic morphology (Stern and Armstrong, 1998; Chevaleyre et al., 2002), and its release into the nucleus is thought to promote bursting activity in

\section{Discussion}

The results presented here allow us to draw two conclusions. The first is that the postsynaptic, or target, cell can control the reliability of inhibitory synaptic inputs through a constitutive action of eCBs at the presynaptic terminal. In the system examined here, the MNCs in the hypothalamus, this requires a perfunctory postsynaptic release of the neuropeptide OT. The second conclusion is that, by maintaining GABA $P_{\mathrm{r}}$ at a relatively low level, this process allows synaptic inhibition to build during highfrequency trains of activity and promotes the cessation of postsynaptic firing. This indicates that, at these synapses, synaptic strengths do not undergo an obligatory normalization process during repetitive synaptic activity (Markram and Tsodyks, 1996; Tsodyks and Markram, 1997; Varela et al., 1997) .

The demonstration that eCBs are responsible for determining synaptic reliability in a constitutive manner further expands on a crucial role for these retrograde messengers in the CNS. We have shown here that, in the hypothalamic magnocellular nuclei, it is these cells (Moos and Richard, 1989; Lambert et al., 1993; Jourdain et al., 1998), which then potentiates hormone release from the posterior pituitary during parturition and lactation.

Previous reports examining the inhibition of glutamatergic synapses in the SON by OT (Kombian et al., 1997) indicate that this inhibition also requires the production of eCBs (Hirasawa et al., 2004). Consequently, we also asked whether the tonic actions of OT were a prerequisite to the production and subsequent actions of eCBs. Because we could effectively mimic the actions of exogenous $\mathrm{OT}$ with exogenous $\mathrm{CB}_{1}$ receptor agonist, block the effects of OT with $\mathrm{CB}_{1}$ antagonist, and, finally, increase $P_{\mathrm{r}}$ by blocking $\mathrm{CB}_{1}$ receptors alone, we conclude that it is the $\mathrm{CB}_{1}$ receptor that is constitutively active on presynaptic terminals and that $\mathrm{OT}$ acts primarily to stimulate the production of the endogenous agonist for the $\mathrm{CB}_{1} \mathrm{R}$. Consistent with previously described schemes for eCB production in which activation of $\mathrm{G}_{\mathrm{q}}$-coupled metabotropic glutamate receptor receptors in postsynaptic neurons recruits intracellular $\mathrm{Ca}^{2+}$ stores to drive the production of 
eCBs (Maejima et al., 2001; Varma et al., 2001; Chevaleyre and Castillo, 2003), the OTR, when activated, also increases intracellular $\mathrm{Ca}^{2+}$ (Lambert et al., 1994). Our findings are unique from previous work on eCBs in which these retrograde messengers are essentially produced "on demand" in response to activity in the postsynaptic cell (Kreitzer and Regehr, 2001; Maejima et al., 2001, 2005; Ohno-Shosaku et al., 2001; Wilson and Nicoll, 2001; Brenowitz and Regehr, 2003; Brown et al., 2003; Hashimotodani et al., 2005). We report the tonic extracellular presence of a messenger, OT, in concentrations that are sufficient for the ongoing production of eCBs. It is the result of this tonic release of the eCB signal that allows the OT neuron to control $P_{\mathrm{r}}$ at its inhibitory synapses. Although there are reports of long-lasting actions of eCBs in the CNS (Bacci et al., 2004), there is only one report demonstrating a tonic action of this messenger on neurotransmitter release (Hentges et al., 2005).

Our observations that the high-frequency activation of inhibitory synapses under tonic OT/eCB control powerfully inhibited spiking in the OT cells raises the possibility that the increase in dendritic OT release during lactation may further sharpen this process and thus promote high-frequency, but very brief, discharges in these cells. This latter observation is particularly intriguing because it provides a surprising observation in the context of how synaptic strength is regulated during repetitive synaptic activation. A number of studies have demonstrated that, at excitatory cortical synapses, repetitive activation of afferent synapses tends to normalize synaptic strength (Markram and Tsodyks, 1996; Abbott et al., 1997; Tsodyks and Markram, 1997; Varela et al., 1997; Abbott and Regehr, 2004). In other words, regardless of the original strength of the synapse, repetitive activation results in a situation in which the strengths of facilitating or depressing synapses converge to a similar value. There have been some exceptions to this compelling proposal: namely, at an auditory glutamatergic synapse, decreasing $P_{\mathrm{r}}$ allows synapses to facilitate beyond the absolute steady-state level observed when synapses depress (Brenowitz et al., 1998). Our results would seem to be consistent with these latter findings, but whether this increase in synaptic strength in facilitating trains is attributable to a relief from postsynaptic receptor desensitization as at auditory synapses (Brenowitz and Trussell, 2001; Wong et al., 2003) is unclear. A slow desensitization of $\mathrm{GABA}_{\mathrm{A}}$ receptors during repetitive activation has been described in other systems (Orser et al., 1994; Jones and Westbrook, 1996; Overstreet et al., 2000) and could conceivably contribute to the depression observed here when $P_{\mathrm{r}}$ is high. It is also equally plausible that, by blocking $\mathrm{CB}_{1}$ receptors, we may be relieving an eCB-driven, $\mathrm{Ca}^{2+}$-dependent inhibition of release machinery (Hsu et al., 1996; Bellingham and Walmsley, 1999) that is recruited selectively during repetitive synaptic activation. The precise mechanisms underlying the observations presented here will require additional exploration.

Although the release of OT can be stimulated by action potentials in the MNC cell body (Kombian et al., 1997), fast, $\mathrm{Na}^{+}{ }_{-}$ channel gated events are not necessary for its release (Ludwig et al., 2002). Recent reports indicating that activation of postsynaptic NMDA receptors may serve as the initial trigger for OT release offer one interesting option through which ongoing synaptic activity may lead to the tonic release of OT (de Kock et al., 2004). One important question raised by these and previous (Hirasawa et al., 2004) findings is why, when eCBs can be produced by activity in the postsynaptic cell, there would be an obligatory requirement for the release of OT. One potential explanation is that these cooperative neuropeptide-eCB actions act to increase the number of synapses that can be controlled by the postsynaptic cell. We know that eCBs have a very localized site of action (approximately a few micrometers) (Brown et al., 2003), yet OT can act on both the cell in which it is produced and neighboring neurons that express functional OTRs. Additionally, as a neuropeptide with no well known active clearance or reuptake process, the duration for which OT can act in the extracellular space is considerably longer than classical transmitter systems, such as glutamate, which have well defined reuptake systems. Thus, the initial release of OT may act to expand the spatial and temporal window of eCB actions, allowing all of the synapses on the target neuron, and perhaps even on neighboring neurons and glial cells, to be controlled in a homogeneous manner. In effect, this would normalize the GABA release probability at all of the synapses onto a given OT target cell. This normalization of afferent inputs has been reported previously at neocortical synapses (Koester and Johnston, 2005), and it is tempting to speculate that the mechanism we describe here in which a slow-acting, nontraditional signal such as a neuropeptide would recruit another molecule to alter $P_{\mathrm{r}}$ may also be implicated in other regions of the brain. The functional impact of our observations is provided by the demonstration of the power of synaptic inhibition on neural activity when all of the synapses onto a given neuron share the same short-term plasticity regimen (Abbott and Regehr, 2004). Under these conditions, the impact of coactivated synapses would be greatly enhanced.

\section{References}

Abbott LF, Regehr WG (2004) Synaptic computation. Nature 431:796-803.

Abbott LF, Varela JA, Sen K, Nelson SB (1997) Synaptic depression and cortical gain control. Science 275:220-224.

Bacci A, Huguenard JR, Prince DA (2004) Long-lasting self-inhibition of neocortical interneurons mediated by endocannabinoids. Nature 431:312-316.

Baimoukhametova DV, Hewitt SA, Sank CA, Bains JS (2004) Dopamine modulates use-dependent plasticity of inhibitory synapses. J Neurosci 24:5162-5171.

Belin V, Moos F (1986) Paired recordings from supraoptic and paraventricular oxytocin cells in suckled rats: recruitment and synchronization. J Physiol (Lond) 377:369-390.

Bellingham MC, Walmsley B (1999) A novel presynaptic inhibitory mechanism underlies paired pulse depression at a fast central synapse. Neuron 23:159-170.

Brenowitz S, Trussell LO (2001) Minimizing synaptic depression by control of release probability. J Neurosci 21:1857-1867.

Brenowitz S, David J, Trussell L (1998) Enhancement of synaptic efficacy by presynaptic GABA(B) receptors. Neuron 20:135-141.

Brenowitz SD, Regehr WG (2003) Calcium dependence of retrograde inhibition by endocannabinoids at synapses onto Purkinje cells. J Neurosci 23:6373-6384.

Brown SP, Brenowitz SD, Regehr WG (2003) Brief presynaptic bursts evoke synapse-specific retrograde inhibition mediated by endogenous cannabinoids. Nat Neurosci 6:1048-1057.

Brussaard AB, Kits KS, de Vlieger TA (1996) Postsynaptic mechanism of depression of GABAergic synapses by oxytocin in the supraoptic nucleus of immature rat. J Physiol (Lond) 497:495-507.

Chevaleyre V, Castillo PE (2003) Heterosynaptic LTD of hippocampal GABAergic synapses: a novel role of endocannabinoids in regulating excitability. Neuron 38:461-472.

Chevaleyre V, Moos FC, Desarmenien MG (2002) Interplay between presynaptic and postsynaptic activities is required for dendritic plasticity and synaptogenesis in the supraoptic nucleus. J Neurosci 22:265-273.

Craig AM, Boudin H (2001) Molecular heterogeneity of central synapses: afferent and target regulation. Nat Neurosci 4:569-578.

Decavel C, van den Pol AN (1990) GABA: a dominant neurotransmitter in the hypothalamus. J Comp Neurol 302:1019-1037.

de Kock CP, Wierda KD, Bosman LW, Min R, Koksma JJ, Mansvelder HD, Verhage M, Brussaard AB (2003) Somatodendritic secretion in oxytocin neurons is upregulated during the female reproductive cycle. J Neurosci 23:2726-2734. 
de Kock CP, Burnashev N, Lodder JC, Mansvelder HD, Brussaard AB (2004) NMDA receptors induce somatodendritic secretion in hypothalamic neurones of lactating female rats. J Physiol (Lond) 561:53-64.

Freund-Mercier MJ, Moos F, Guerne Y, Richard P (1983) Possible control by oxytocin of periodical and synchronous neurosecretory bursts of oxytocin cells. Prog Brain Res 60:197-201.

Gies U, Theodosis DT (1994) Synaptic plasticity in the rat supraoptic nucleus during lactation involves GABA innervation and oxytocin neurons: a quantitative immunocytochemical analysis. J Neurosci 14:2861-2869.

Gupta A, Wang Y, Markram H (2000) Organizing principles for a diversity of GABAergic interneurons and synapses in the neocortex. Science 287:273-278.

Hashimotodani Y, Ohno-Shosaku T, Tsubokawa H, Ogata H, Emoto K, Maejima T, Araishi K, Shin HS, Kano M (2005) Phospholipase Cbeta serves as a coincidence detector through its $\mathrm{Ca}^{2+}$ dependency for triggering retrograde endocannabinoid signal. Neuron 45:257-268.

Hentges ST, Low MJ, Williams JT (2005) Differential regulation of synaptic inputs by constitutively released endocannabinoids and exogenous cannabinoids. J Neurosci 25:9746-9751.

Hirasawa M, Schwab Y, Natah S, Hillard CJ, Mackie K, Sharkey KA, Pittman QJ (2004) Dendritically released transmitters cooperate via autocrine and retrograde actions to inhibit afferent excitation in rat brain. J Physiol (Lond) 559:611-624.

Hsu SF, Augustine GJ, Jackson MB (1996) Adaptation of $\mathrm{Ca}^{2+}$-triggered exocytosis in presynaptic terminals. Neuron 17:501-512.

Jones MV, Westbrook GL (1996) The impact of receptor desensitization on fast synaptic transmission. Trends Neurosci 19:96-101.

Jourdain P, Israel JM, Dupouy B, Oliet SH, Allard M, Vitiello S, Theodosis DT, Poulain DA (1998) Evidence for a hypothalamic oxytocin-sensitive pattern-generating network governing oxytocin neurons in vitro. J Neurosci 18:6641-6649.

Koester HJ, Johnston D (2005) Target cell-dependent normalization of transmitter release at neocortical synapses. Science 308:863-866.

Kombian SB, Mouginot D, Pittman QJ (1997) Dendritically released peptides act as retrograde modulators of afferent excitation in the supraoptic nucleus in vitro. Neuron 19:903-912.

Kombian SB, Hirasawa M, Mouginot D, Chen X, Pittman QJ (2000a) Shortterm potentiation of miniature excitatory synaptic currents causes excitation of supraoptic neurons. J Neurophysiol 83:2542-2553.

Kombian SB, Mouginot D, Hirasawa M, Pittman QJ (2000b) Vasopressin preferentially depresses excitatory over inhibitory synaptic transmission in the rat supraoptic nucleus in vitro. J Neuroendocrinol 12:361-367.

Kombian SB, Hirasawa M, Mouginot D, Pittman QJ (2002) Modulation of synaptic transmission by oxytocin and vasopressin in the supraoptic nucleus. Prog Brain Res 139:235-246.

Kreitzer AC, Regehr WG (2001) Cerebellar depolarization-induced suppression of inhibition is mediated by endogenous cannabinoids. J Neurosci 21:RC174(1-5).

Lambert RC, Moos FC, Richard P (1993) Action of endogenous oxytocin within the paraventricular or supraoptic nuclei: a powerful link in the regulation of the bursting pattern of oxytocin neurons during the milkejection reflex in rats. Neuroscience 57:1027-1038.

Lambert RC, Dayanithi G, Moos FC, Richard P (1994) A rise in the intracellular $\mathrm{Ca}^{2+}$ concentration of isolated rat supraoptic cells in response to oxytocin. J Physiol (Lond) 478:275-287.

Ludwig M, Pittman QJ (2003) Talking back: dendritic neurotransmitter release. Trends Neurosci 26:255-261.

Ludwig M, Sabatier N, Bull PM, Landgraf R, Dayanithi G, Leng G (2002) Intracellular calcium stores regulate activity-dependent neuropeptide release from dendrites. Nature 418:85-89.

Maejima T, Hashimoto K, Yoshida T, Aiba A, Kano M (2001) Presynaptic inhibition caused by retrograde signal from metabotropic glutamate to cannabinoid receptors. Neuron 31:463-475.

Maejima T, Oka S, Hashimotodani Y, Ohno-Shosaku T, Aiba A, Wu D, Waku K, Sugiura T, Kano M (2005) Synaptically driven endocannabinoid release requires $\mathrm{Ca}^{2+}$-assisted metabotropic glutamate receptor subtype 1 to phospholipase $\mathrm{C} \beta 4$ signaling cascade in the cerebellum. J Neurosci 25:6826-6835.

Markram H, Tsodyks M (1996) Redistribution of synaptic efficacy between neocortical pyramidal neurons. Nature 382:807-810.

Moos F, Richard P (1989) Paraventricular and supraoptic bursting oxytocin cells in rat are locally regulated by oxytocin and functionally related. J Physiol (Lond) 408:1-18.

Moos FC (1995) GABA-induced facilitation of the periodic bursting activity of oxytocin neurones in suckled rats. J Physiol (Lond) 488:103-114.

Neumann I, Ludwig M, Engelmann M, Pittman QJ, Landgraf R (1993) Simultaneous microdialysis in blood and brain: oxytocin and vasopressin release in response to central and peripheral osmotic stimulation and suckling in the rat. Neuroendocrinology 58:637-645.

Ohno-Shosaku T, Maejima T, Kano M (2001) Endogenous cannabinoids mediate retrograde signals from depolarized postsynaptic neurons to presynaptic terminals. Neuron 29:729-738.

Ohno-Shosaku T, Hashimotodani Y, Maejima T, Kano M (2005) Calcium signaling and synaptic modulation: regulation of endocannabinoidmediated synaptic modulation by calcium. Cell Calcium 38:369-374

Orser BA, Wang LY, Pennefather PS, MacDonald JF (1994) Propofol modulates activation and desensitization of GABAA receptors in cultured murine hippocampal neurons. J Neurosci 14:7747-7760.

Overstreet LS, Jones MV, Westbrook GL (2000) Slow desensitization regulates the availability of synaptic $\mathrm{GABA}_{\mathrm{A}}$ receptors. J Neurosci 20:7914-7921.

Poulain DA, Wakerley JB, Dyball RE (1977) Electrophysiological differentiation of oxytocin- and vasopressin-secreting neurones. Proc R Soc Lond B Biol Sci 196:367-384.

Pow DV, Morris JF (1989) Dendrites of hypothalamic magnocellular neurons release neurohypophysial peptides by exocytosis. Neuroscience 32:435-439.

Randle JC, Renaud LP (1987) Actions of gamma-aminobutyric acid on rat supraoptic nucleus neurosecretory neurones in vitro. J Physiol (Lond) 387:629-647.

Renaud LP, Bourque CW (1991) Neurophysiology and neuropharmacology of hypothalamic magnocellular neurons secreting vasopressin and oxytocin. Prog Neurobiol 36:131-169.

Reyes A, Lujan R, Rozov A, Burnashev N, Somogyi P, Sakmann B (1998) Target-cell-specific facilitation and depression in neocortical circuits. Nat Neurosci 1:279-285.

Roland BL, Sawchenko PE (1993) Local origins of some GABAergic projections to the paraventricular and supraoptic nuclei of the hypothalamus in the rat. J Comp Neurol 332:123-143.

Rozov A, Burnashev N, Sakmann B, Neher E (2001) Transmitter release modulation by intracellular $\mathrm{Ca}^{2+}$ buffers in facilitating and depressing nerve terminals of pyramidal cells in layer $2 / 3$ of the rat neocortex indicates a target cell-specific difference in presynaptic calcium dynamics. J Physiol (Lond) 531:807-826.

Stern JE, Armstrong WE (1997) Sustained outward rectification of oxytocinergic neurones in the rat supraoptic nucleus: ionic dependence and pharmacology. J Physiol (Lond) 500:497-508.

Stern JE, Armstrong WE (1998) Reorganization of the dendritic trees of oxytocin and vasopressin neurons of the rat supraoptic nucleus during lactation. J Neurosci 18:841-853.

Theodosis DT, Paut L, Tappaz ML (1986) Immunocytochemical analysis of the GABAergic innervation of oxytocin- and vasopressin-secreting neurons in the rat supraoptic nucleus. Neuroscience 19:207-222.

Tsodyks MV, Markram H (1997) The neural code between neocortical pyramidal neurons depends on neurotransmitter release probability. Proc Natl Acad Sci USA 94:719-723.

van den Pol AN (1982) The magnocellular and parvocellular paraventricular nucleus of rat: intrinsic organization. J Comp Neurol 206:317-345.

Varela JA, Sen K, Gibson J, Fost J, Abbott LF, Nelson SB (1997) A quantitative description of short-term plasticity at excitatory synapses in layer $2 / 3$ of rat primary visual cortex. J Neurosci 17:7926-7940.

Varma N, Carlson GC, Ledent C, Alger BE (2001) Metabotropic glutamate receptors drive the endocannabinoid system in hippocampus. J Neurosci 21:RC188(1-5).

Watanabe J, Rozov A, Wollmuth LP (2005) Target-specific regulation of synaptic amplitudes in the neocortex. J Neurosci 25:1024-1033.

Wilson RI, Nicoll RA (2001) Endogenous cannabinoids mediate retrograde signalling at hippocampal synapses. Nature 410:588-592.

Wong AY, Graham BP, Billups B, Forsythe ID (2003) Distinguishing between presynaptic and postsynaptic mechanisms of short-term depression during action potential trains. J Neurosci 23:4868-4877.

Zucker RS, Regehr WG (2002) Short-term synaptic plasticity. Annu Rev Physiol 64:355-405. 